Research Article

\title{
Construction of a Teaching System Based on Big Data and Artificial Intelligence to Promote the Physical Health of Primary School Students
}

\author{
Zhonglin Ma, ${ }^{1}$ Changcheng Xin $\mathbb{D}^{2,3}$ and Huifang Zheng ${ }^{4}$ \\ ${ }^{1}$ College of Physical Education, Jilin Normal University, Siping, Jilin 136000, China \\ ${ }^{2}$ Graduate School, Jose Rizal University, Mandaluyong 1550, Metro Manila, Philippines \\ ${ }^{3}$ Qidong Huilong Middle School, Nantong, Jiangsu 226200, China \\ ${ }^{4}$ College of Physical Education, Lanzhou City University, Lanzhou, Gansu 730070, China
}

Correspondence should be addressed to Changcheng Xin; hlzxxcc@163.com

Received 5 May 2021; Revised 19 May 2021; Accepted 27 May 2021; Published 7 June 2021

Academic Editor: Sang-Bing Tsai

Copyright (C) 2021 Zhonglin Ma et al. This is an open access article distributed under the Creative Commons Attribution License, which permits unrestricted use, distribution, and reproduction in any medium, provided the original work is properly cited.

In recent years, although the overall physical health of Chinese students has shown an upward trend, the substantial decline in student physical fitness has been basically curbed. Most of the physical health indicators of students are steadily improving, but there are still many problems that need to be vigilant. In order to solve the problem of the decline of the physical health of primary school students, it is very important to construct a teaching system based on big data and artificial intelligence to promote the physical health of primary school students. This article aims to study from the actual situation and find scientific and reasonable methods to improve the physical health of primary school students. This article uses the literature method, questionnaire survey method, mathematical statistics method, and other research methods to analyze and study the current physical condition of the interviewed students and the actual influencing factors by taking students from 5 domestic primary schools as the research object. It is concluded that more than $90 \%$ of primary school students in Haidian District, Beijing, have good physique and physical development. The development level of strength and flexibility is gradually improved, but the speed and endurance quality are on the decline, especially the endurance quality of primary school boys has declined the most. Lack of good exercise habits, insufficient exercise time and exercise efficiency, and lack of appropriate exercise volume and necessary exercise intensity are currently the most important factors affecting the physical health of primary school students. The physical problems of primary school students are not caused by a single factor, but the result of multiple factors. This article puts forward a number of suggestions for the above situation and problems to be solved urgently.

\section{Introduction}

1.1. Background. Nowadays, with the progress and development of the society and the rise of the economy, citizens have to pay for these enjoyments while enjoying the convenience of modern life. We are facing a series of problems such as environmental pollution, unsanitary food, and air pollution. These seemingly disharmonious phenomena hinder civilized life; our physique has been severely tested. The superiority of material conditions, the elders' love of the only child, and the various bad habits of parents continue to affect young people. Now not only in cities, but also in rural areas, children can see children playing with technology products such as mobile phones and computers after school. The physical condition of children and adolescents is worrisome, and their physical health should arouse the attention of the whole society. With the rapid development and advancement of society, people's health awareness has become stronger and stronger, and the attention paid to the physical health of students from all walks of life in the society has reached an unprecedented height. Accordingly, the country is constantly revising and improving the "students' physical fitness." Health standards, the latest revision was in 2014 and formally implemented in 2015. According to 
national requirements, domestic primary schools conduct physical fitness tests on students every year. The test data is compared with the "standards," but the situation is not optimistic. The physical health of students has not been well developed, especially in terms of sports quality. Therefore, it is necessary to strengthen the theoretical research on the physical health of primary school students, find the factors that affect their improvement and intervene early to lay a good theoretical foundation for the sustainable development of the physical health of students. And this article aims to establish a brand-new model based on big data and artificial intelligence technology to promote the physical health of primary school students.

1.2. Significance. Based on the standard, this paper draws on the existing evaluation model and index research system of pupils' physical fitness, tries to use big data and artificial intelligence-based health promotion model teaching, builds a grading model based on the new index system, and tests the accuracy of the model. And finally, it gives corresponding conclusions on the physical health of primary school students. The sample research shows that this evaluation model has relatively good accuracy and operability and can comprehensively classify and evaluate individual students or student groups, making the work of assessing the physical health of primary school students more scientific and intelligent. Compared with the existing methods for assessing the physical fitness of students, the classification model constructed in this article reduces the number of calculation steps. It only needs to implement a single calculation to obtain the physical fitness categories of the student group or individual, without the need to compare each individual. Searching for the scores of the class indicators complicates the process of calculating the weights. At the same time, this model can fully consider the subjective initiative in the process of manual evaluation and can overcome the limitations of manual evaluation. It is one of the evaluation methods that combine quantitative and qualitative evaluation. The first simulation test is not only a comprehensive evaluation and scoring model, but also a more effective, simple, and scientific evaluation of college students' physical health. More importantly, the model can quantitatively analyze the development trend of primary school students' physical health, arouse the attention and warning of parents and society, and promote them to form the habit of selfmonitoring and evaluation. Targeted physical exercise provides a firm confidence for promoting the reform of physical education and the intelligent development of primary school students' physical health evaluation. All in all, the research on the physical health of primary school students and the prediction of subsequent development are of crucial significance. Through continuous exploration and discovery in this area, I believe that the ultimate goal of improving the physical health of students can be finally achieved.

1.3. Related Work. With the development and application of technology, educators' research on intelligent teaching systems is increasingly on the agenda. Among them, in order to improve the level of intelligence, the application of artificial intelligence technology is the most prominent. Kim et al. proposed that the purpose of this research is to understand the working mechanism of various voluntary compliance behaviors and how to use information technology in a corporate environment where the development of big data and artificial intelligence has made privacy and security issues become critical. Compliance management is conducted. In this research, we propose a structural model based on the theory of planned behavior and the view of IT relevance, in which behavioral beliefs about compliance, social pressure, and compliance knowledge affect compliance intentions, while the knowledge of compliance is very important for the construction of this structural model. The influence of behavioral beliefs and social pressure is mediated to compliance intentions. The influence of the three variables differs between the two groups, depending on the utilization of the compliance support system. Although the development of big data and artificial intelligence is developing very fast, it also brings many potential hidden dangers, such as personal privacy leakage and other issues [1]. Haji and Azmani proposed that the focus of this article is to provide education and career guidance for the modeling of an intelligent digital ecosystem for students and young people seeking a first job or retraining. To this end, the multiexpert system paradigm was used to aggregate the different expertise required for good guidance, and the multiagent system principle was used to establish a modular and easily expandable ecosystem. Indeed, the agents of the system communicate with each other with a collaborative perspective and use the FIPA-ACL language during the entire directional assistance process to perform tasks such as proposing business departments, occupations, training, and training paths. The ontology of the Semantic Web has been used to carry out a complete semantic description of shared information and promote the communication between different software agents in the ecosystem [2]. Boratia et al. proposed that the purpose of this study was to analyze the self-perception of sixth-grade primary school students' physical activity levels and compare it with the views of their physical education teachers. A representative questionnaire survey of older children's physical activity was conducted among 329 6th grade elementary school students (11-12 years old) from 31 education centers in La Rioja. Similarly, the physical education teachers in each center also filled out the questionnaire in duplicate and reported their views on boys and girls. He also wants to know the release time. The physical activity level of boys is statistically higher, especially in physical education classes, breaks, and weekends [3]. In the last two cases, teachers are aware of these differences.

1.4. Main Content. This article focuses on the shortcomings of traditional fitness methods, combining "Internet + " and "big data machine learning" technology to design and implement a new teaching system for the physical health promotion of primary school students. The health promotion mode teaching system is equipped with corresponding exercise APP to realize the combination of "Internet +" and exercise, and the near-field communication (NFC) 
technology is used to realize the networking of exercise equipment. Users can view their exercise information through the exercise APP. At the same time, the user's exercise data is processed by building a big data processing platform, and machine learning technology is used to realize intelligent recommendation of exercise equipment. By comparing mainstream big data platforms, this article chooses Spark as the system's big data processing platform. And it uses multiple computers to independently build a Spark cluster system based on the Hadoop platform and introduce the Spark cluster running mode and key configuration steps [4]. Use Spark's SQL function to extract the user's exercise data from the server database of the physical fitness promotion model teaching system and use machine learning technology to analyze and process the queried data on the big data platform and use the matrix decomposition method provided by Spark to achieve exercise Intelligent recommendation system for body equipment. In this paper, because the physical fitness promotion mode teaching system does not have enough user exercise data, the MovieLens data set is used to simulate the data set of the exercise system for intelligent recommendation of exercise equipment [5].

\section{Physical Health Promotion Model Method}

\subsection{The Design of the Teaching System of the Physical Health Promotion Model}

2.1.1. System Logical Architecture. Generally speaking, the basic logical structure of the physical health promotion model teaching system is roughly composed of three basic modules: student module, teacher module, and knowledge base [6], as shown in Figure 1.

Student module: the module of recording students' personal information, course information, and test questions information. Through this module, teachers can master students' basic information, learning ability, and knowledge mastery, analyze students' current situation information, correctly judge students' understanding of knowledge, and adopt corresponding teaching methods to teach students [7].

Teacher module: it is through understanding the various information of students to research suitable teaching strategies for students and to select the teaching content for students to learn and show them to students in a form that students can accept, so that teachers can see the ingenious guidance and ingenuity of teachers. The teaching level is superb. Teachers can use this system to master students' basic information, learning abilities, knowledge, and test results and then make corresponding teaching arrangements. Teachers can also update the knowledge base according to the various information of the students and formulate more suitable for students.

Expert knowledge module: it is the knowledge base, which is used to store all the teaching knowledge to facilitate students' learning and provide students with the knowledge they want to learn. The characteristics of the knowledge base are easy to operate and easy to use, and it is the need for solving problems in the expert knowledge domain. Use

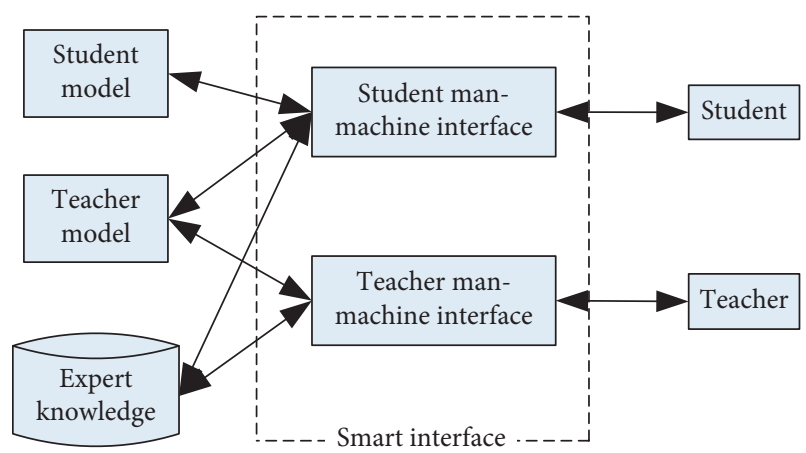

FIGURE 1: Logical structure of the intelligent teaching system.

knowledge storage to store, organize, and manage all teaching knowledge in computer memory [8]. It can be called by other modules.

2.1.2. System Topology. This intelligent teaching system is mainly provided by application server, database server, Web server, etc., and teachers, administrators, and students can access the system through the Internet $[9,10]$. Among them, the database server is mainly used to store various teaching resources, such as the personal information database in the student and teacher model, the domain knowledge base, the teaching knowledge base in the teacher model, and the learning/test history database as shown in Figure 2.

2.2. Combination Forecasting Model. Although both traditional prediction methods and artificial intelligence methods can achieve good prediction results in some fields, the disadvantages of a single method make it impossible to further improve the prediction accuracy [11, 12]. For example, the traditional prediction method can effectively deal with the prediction of linear data, while the artificial intelligence method can well deal with the prediction of nonlinear data, but most of the data at this stage contain both linear part and nonlinear part, only combining the advantages of the two can better solve the problem. At the same time, the first model can be widely used in different fields. The combination model can dynamically adjust the weight of each method according to different data and has achieved good results in many fields. The main idea of the combined model [13] is to form a new prediction method by dynamically combining different single models according to the different inherent characteristics of the data.

\subsection{Research Methods of the Physical Health Promotion Model}

2.3.1. Data Research Method. On China Knowledge Network, "Chinese Journal Full-Text Database," Shandong Normal University Library, Chaoxing Digital Library, and related websites check and read literature and books related to physical fitness, health, and health promotion. Enter "Physical Health" and include "Youth"; also include "countermeasures" or "promotion methods" or "optimization approaches" [14], and they have received nearly 2,000 


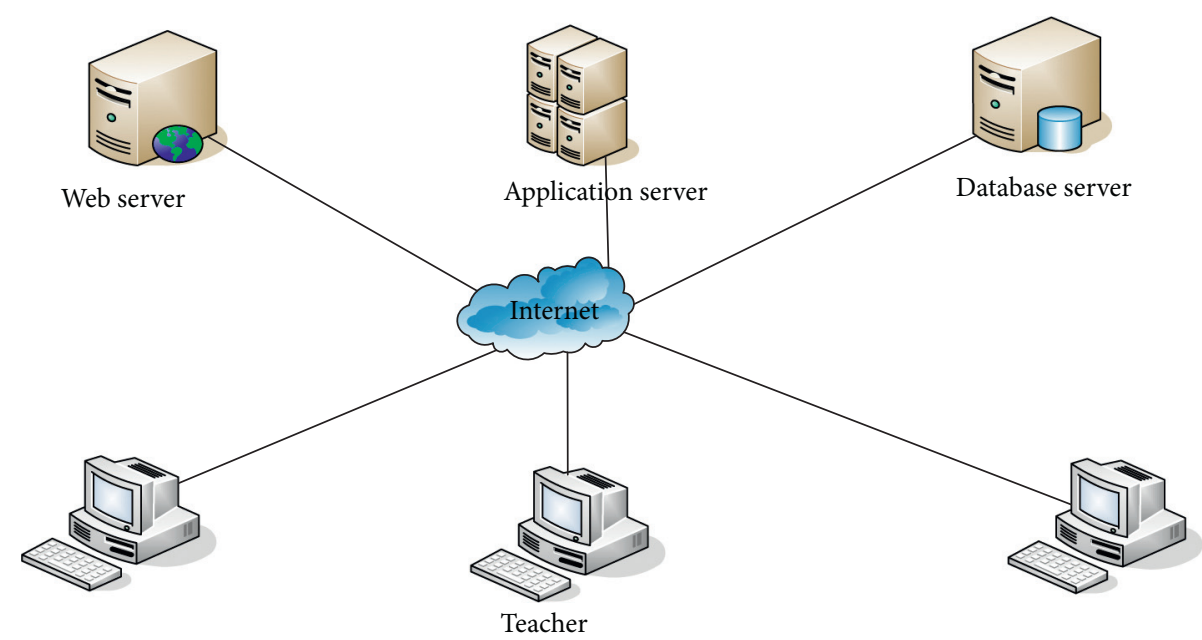

FIgURE 2: Topological structure diagram.

articles, and the number of articles posted is increasing year by year. And to screen the literature, screen the literature that has reference significance or value for this research, download and screen; the result is shown in Figure 3.

2.3.2. Questionnaire Survey Method. A random cluster sampling method was used to select a total of 500 students from 11 primary schools in China and issue questionnaires. The issuance and recovery of the questionnaire is carried out by the physical education team leader of the school under investigation. Because the age span of the students under investigation is relatively large, the teacher in charge of the questionnaire will ask each question one by one during the process of tuning the questionnaire. After the explanation, students fill in the questions one by one. The teacher instructs the students to collect them all on the spot after filling in. The teacher questionnaire was distributed and collected by the sports team leader of each surveyed school. All the questionnaires of the 500 students who received the questionnaire survey were returned, which was 500 copies, and the recovery rate was $100 \%$. In the later process of data statistics, 9 invalid questionnaires were found. The actual valid questionnaires were 491, and the questionnaire effective rate was $98.2 \%$. There are 20 teacher questionnaires, 20 of which were returned. There were 20 valid questionnaires, and the effective response rate was $100 \%$. The validity of the questionnaire was tested through expert interviews, e-mails, and phone calls. Twelve experts and scholars gave evaluations. The questionnaire validity evaluations are listed in the table below. In terms of the questionnaire's test reliability, the test-retest method is used to test the validity: the same questionnaire is tested one week before and after the test (1/10 is drawn for retesting when retesting), and the testretest reliability is 0.82 , indicating that this study adopts the retest method to test the validity with a certain degree of scientificity. The questionnaire is of use value and can meet the needs of this research.

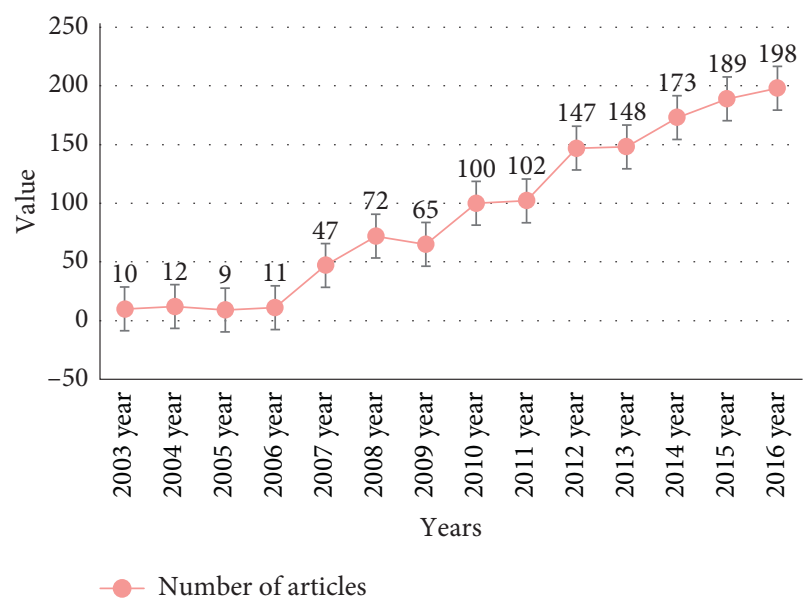

FIgURE 3: China CNKI's publication volume chart on the physical health of adolescents.

2.3.3. Mathematical Statistics. In the process of research, this paper uses EXCEL software and SPSS software (17.0) to statistically analyze and process the data collected, questionnaires, and experiments [15].

\section{Data Preprocessing Experiment}

3.1. Wavelet Transform. In the field of signal analysis, the Fourier transform (FT) [16] is the earliest used. This method changes the whole system and can deal with the frequency information of traditional stationary signal effectively. However, most of the existing information at this stage contains nonstationary information, that is, most of the signal changes depending on time changes, so the Fourier transform cannot show the local characteristics of the signal. The improved short-time Fourier transform uses a windowing method to perform a certain degree of time-frequency analysis, but for time-varying nonstationary signals, 
different frequencies are suitable for different width windows, and the short-time Fourier transform with fixed window size still shows defect. After a famous French scholar applied wavelet to the decomposition of multiple signals in 1984, the method has been continuously optimized. Based on the Fourier transform, wavelet transform can effectively analyze nonstationary signals while also processing signal sudden changes. Wavelet analysis has a bright future in the field of signal noise reduction and recognition [17].

For a given function, $\psi(T) \in L^{2}(R)$, where $L^{2}(R)$ can be recorded as a square integrable real number space, $\psi^{\wedge}(T)$. The Fourier transform is denoted as $\psi(T)$ when $\psi(T)$ and $\psi^{\wedge}(T)$ meet the following permissible premises:

(a) $\psi(T)$ is a continuous function and exhibits a certain exponential decay characteristic, $\psi(T) \leq M e^{-C|x|}$ and, $C$ and $M$ are constants

(b) The integral of $\psi(T)$ is 0 , which is $\int_{R} \psi(x) \mathrm{d} x=0$

(c) $C_{\psi}=\left(\int_{R}\left|\psi^{\wedge}(T)\right|^{2} /|w| \mathrm{d} w<\infty\right)$

Then, $\psi(T)$ is regarded as a mother wavelet function, and a series of functions $\left\{\psi_{a, b}(T)\right\}$ are formed after scaling and translation of the corresponding function:

$$
\psi_{a, b}(T)=\frac{1}{\sqrt{a}} \psi\left(\frac{T-b}{a}\right) .
$$

In this function $\psi_{a, b}(T)$ is a subwavelet, $a$ is a scale factor or scaling factor, and $b$ is a time factor or translation factor.

If any $f(T)$ in the signal space $L^{2}(R)$ with limited energy is expanded under the wavelet basis, then $f(T)$ is regarded as its continuous wavelet transform (CWT) [18]:

$$
\begin{aligned}
\operatorname{CWT}(a, b) & =\frac{1}{\sqrt{a}} \int_{R} f(T) \psi\left(\frac{x-b}{a}\right) \mathrm{d} T \\
& =\iint_{-\infty}^{+\infty} f(T) \psi_{a, b}^{*}(T) \mathrm{d} T,
\end{aligned}
$$

where $\psi_{a, b}^{*}(T)$ is the conjugate function of $\psi_{a, b}(T)$. Because the wavelet basis contains two parameters of scale and displacement, the expansion of the wavelet basis is actually to project a certain one-dimensional time function onto the corresponding two-dimensional phase plane. The coordinate axis of this plane is time and scale; that is, the signal carried out the upgrade operation.

In practical applications, CWT will produce redundant components of some information. In order to avoid the appearance of redundant components, the wavelet function is often discretized, that is, discretize and instead of time.

Take $a=2^{-j}, b=n 2^{-j}, n \in Z$, and discretize the signal $f(t)$, that is, DWT, we can get

$$
\operatorname{DWT}(a, b)=2^{(j / 2)} \int_{-\infty}^{+\infty} f(T) \psi\left(2^{j} T-n\right) \mathrm{d} T .
$$

3.2. Mallat Tower Algorithm. Mallat [19], [28] algorithm discretizes both in time and scale, which not only reduces the amount of calculation, but also shortens the calculation time, which is called fast wavelet transform [20]. Zoom and pan the scale function to get

$$
\phi\left(2^{-j} T-k\right)=\sum h(n) \phi\left(2^{-j+1} T-2 k-n\right) .
$$

For any $1 f(t)=V_{j-1}$, expand in $V_{j-1}$ space

$$
f(T)=\sum c_{j-1, k} 2^{((-j+1) / 2)} \phi\left(2^{-j} T-k\right) .
$$

Decomposing the signal $f(t)$, we can get

$$
\begin{aligned}
f(T)= & \sum c_{j-1, k} 2^{((-j+1) / 2)} \phi\left(2^{-j} T-k\right) \\
& +\sum_{k} d_{j, k} 2^{-(j / 2)} \psi\left(2^{-j} T-k\right) .
\end{aligned}
$$

At this time, the expansion of the signal in the $j$ scale can be obtained, which usually includes two frequencies, high (denoted as $d_{j, k}$ ) and low (denoted as $c_{j, k}$ ). Letting $m=2 k+n$, we have

$$
\begin{aligned}
& c_{j, k}=\sum_{m} h(m-2 k) c_{j-1, m}, \\
& d_{j, k}=\sum_{m} g(m-2 k) c_{j-1, m} .
\end{aligned}
$$

Among them, $h(m-2 k)$ and $g(m-2 k)$ are low-pass filter and high-pass filter, respectively. From the above analysis, we can see that by continuing to decompose the remaining scale coefficients in the space, any scale space and corresponding coefficients can be obtained.

\subsection{Introduction to the Combined Model Method}

3.3.1. Extreme Learning Machine. Like other neural networks, ELM is also composed of three neuron layers [21]: an input layer, a hidden layer, and an output layer. The specific steps of this method are described as follows:

The problem handled by ELM can be transformed into a dual problem:

$$
L_{\mathrm{ELM}}=\frac{1}{2}\|\delta\|^{2}+\frac{1}{2} C \sum_{i=1}^{N}\|\delta\|^{2}-\sum_{i=1}^{n} \sum_{j=1}^{m} \alpha_{i, j}\left(h\left(x_{i}\right) \delta_{j}-t_{i, j}+\xi_{i, j}\right.
$$

Therefore, the expression for the weight of the output layer can be obtained as follows:

$$
\delta=H^{T}\left(\frac{1}{C}+H H^{T}\right)^{-1} T .
$$

In formulas (2)-(5), $C$ represents the penalty factor, $\alpha_{i, j}$ is the Lagrange multiplier, $\xi_{i}$ is the training error, and $T$ is recorded as the output matrix. 
Taking the calculated into account, the output expression is

$$
f(x)=h(x) \delta=h(x) H^{T}\left(\frac{1}{C}+H H^{T}\right)^{-1} T .
$$

3.3.2. C-C Method. If the time series are independent and identically distributed, when $N \longrightarrow \infty$, for a fixed $m$ and $t$, the statistic $s_{2}(m, r, t)$ is always zero [22]. However, in actual calculations, the length of the specified sequence must be a predetermined constant, which means that $s_{2}(m, r, t)$ can never be 0 . Therefore, the optimal solution of $\tau_{d}$ is at the zero point that is first obtained or found or the first local minimum point.

After selecting the maximum and minimum radius, the error between the two can be defined as follows:

$$
\Delta s_{2}(m, t)=\max \left\{s_{2}(m, r, t)\right\}-\min \left\{s_{2}(m, r, t)\right\} .
$$

According to the BDS statistical theory [23], the three equations can be calculated as follows:

$$
\begin{aligned}
\overline{s_{2}}(t) & =\frac{1}{16} \sum_{m=2}^{5} \sum_{i=1}^{4} s_{2}\left(m, r_{i}, t\right), \\
\Delta \overline{s_{2}}(t) & =\frac{1}{4} \sum_{m=2}^{5} \Delta s_{2}(m, t), \\
s_{2 \text { cor }}(t) & =\Delta \overline{s_{2}}(t)+\mid \overline{s_{2}(t)} .
\end{aligned}
$$

When $N=3000, r=k \times(\sigma / 2)$, and $\sigma=\operatorname{std}(x)$ (representing the standard deviation), the optimal delay time $\tau_{d}$ is the first value of $\overline{s_{2}}(t)$ or the first minimum value of $\Delta \overline{s_{2}}(t)$. If you fully consider $\overline{s_{2}}(t)$ and $\Delta \overline{s_{2}}(t)$, when $s_{2 \text { cor }}(t)$ is the global minimum, the length of the time window can be obtained.

\section{Reasons Affecting the Physical Health of Primary School Students}

School physical education is the basis for guiding students to participate in physical activities, and exercise is the main guide to improve the quality of the main body. In order to better implement quality education, school physical education, physical education courses, and extracurricular sports activities are actively carried out $[24,25]$. In the survey, we found that one of the most important factors for the physical health of urban children to be higher than that of rural students is that urban schools pay more attention to the development of school sports, and the physical education curriculum in Tianqiao District is not taken seriously. Physical education curriculum is the foundation of school physical education. The school attaches great importance to physical education and pays attention to the physical health of students. For example, in terms of height, the average height is higher than that of rural students at the same age. In addition to genetic factors, the acquired environment affects them. It is also very important, especially physical exercise has a positive effect on height. This requires school leaders to strengthen the importance of physical education, raise the awareness of sports by the whole people, and infect all teachers and students. Nowadays, some schools in the district believe in "examination-oriented education," which has caused a heavy burden on students' schoolwork. Study time squeezes out students' time for games, playing, and exercise. Sometimes, physical education classes are also occupied by teachers of other subjects [26]; therefore, it is imperative to make teachers in the whole district aware of the concept of "no performance without physical education," and to raise their awareness is imperative. Physical education teachers should reasonably explain related knowledge about sports and health in class, so that students, including their parents, have similar knowledge, and the improvement of their ideological awareness will also make the students' physical health status benign development.

4.1. School Venues Are Not Full of Equipment and Sports Classroom Time Is Squeezed. It can be clearly seen from Table 1 that 245 people indicated that they often have contact with other classes in the learning process of physical education. Through field understanding, it is found that these contacts are caused by the lack of venue distance between classes. How much is the same time period? A class is engaged in physical education, but most schools only have a track and field. There are no other sports venues. This results in students' physical education classrooms often being in contact with other classes, which greatly reduces the safety factor of the physical education classroom and the students' learning concentration so that the learning effect of students is reduced, and the effect of improving physical fitness of students in physical education class is also affected [27]. At the same time, we can also see from the table that only $1.02 \%$ of the students surveyed stated that they always have a venue for physical exercise during their spare time. More than half of the students believe that venues for extracurricular activities are only occasionally available and basically not available. Meet the needs of students' extracurricular exercises.

From Table 2, we can see the status of school equipment in the eyes of students. $46.84 \%$ of students think that the types of sports equipment available in the school are too few, followed by $29.74 \%$ of students who think that the existing sports equipment in the school is obsolete, and $20.37 \%$ of students think that the color of the school's existing equipment is too single, and only $3.05 \%$ of the students think that the school's existing sports equipment is colorful and can meet various needs.

It can be seen from the above table that the existing sports venues and equipment cannot meet the needs of sports. Through on-site understanding and communication with teachers, it is found that not only the venue is not enough to meet the needs of students for physical exercise, but also that the existing equipment in the school is also 
TABLE 1: School site survey form.

\begin{tabular}{|c|c|c|c|c|c|}
\hline & Frequency & $\begin{array}{c}\text { There has never } \\
\text { been }\end{array}$ & Occasionally & Often & Always have \\
\hline \multirow{2}{*}{$\begin{array}{l}\text { Contact between the physical education class and other } \\
\text { classes }\end{array}$} & $\begin{array}{l}\text { Number of } \\
\text { people }\end{array}$ & 26 & 220 & 245 & 0 \\
\hline & Proportion & $5.30 \%$ & $44.81 \%$ & $49.90 \%$ & $0.00 \%$ \\
\hline \multirow[t]{2}{*}{ Situation of exercise venues in spare time } & $\begin{array}{c}\text { Number of } \\
\text { people }\end{array}$ & 0 & 270 & 216 & 5 \\
\hline & Proportion & $0 \%$ & $54.99 \%$ & $43.99 \%$ & $1.02 \%$ \\
\hline
\end{tabular}

TABLE 2: Statistics of school equipment.

\begin{tabular}{lcccc}
\hline Attitude & Outdated equipment & Less equipment & Single color of equipment & Colorful school equipment \\
\hline Number of people & 146 & 230 & 100 & 15 \\
Proportion & $29.74 \%$ & $46.84 \%$ & $20.37 \%$ & $3.05 \%$ \\
\hline
\end{tabular}

insufficient in variety and quantity, and the equipment is not attractive to students, the equipment is updated slowly, and the color is single [19].

From Figures 4 and 5, we can clearly see that nearly 95\% of the students surveyed indicate that the school physical education class is occupied by other teachers, and even nearly half of the students indicate that the physical education classroom is often squeezed. Only 3.05\% of the students stated that there was never homework in the classroom, and $95 \%$ of the students expressed more or less homework. The surveyed students' extracurricular learning situation is similar to the school's homework situation. Only $3.05 \%$ of the students have never attended an extracurricular class. Nearly, $97 \%$ of the students are more or less involved in the extracurricular learning. In addition to classroom learning, it also brings a lot of learning burden to students. After field investigation and communication with students, it is found that in the learning process, schoolwork is heavy. In addition to learning classroom knowledge, we have to attend various cram classes. When the spare time is occupied, there is also the occupation of physical education. Through the on-the-spot communication with the students, we know that the occupation of students' physical education is mainly concentrated near the final exam, the weather conditions are not ideal, and physical education will also be occupied by other teachers.

From Tables 3 and 4, it can be seen that most of the students surveyed still like physical education classes. However, because the content of the class is too single, most of the class exercises are based on individual exercises, and the form of class exercises is single, which finally makes physical education The teaching effect of the classroom is not good, and the physical quality of the students cannot be well developed. After field investigation, it is found that students think that the physical education class is boring, the exercise content is single, and the exercise content is mostly personal exercises, which leads to the fact that the students cannot enter the physical education class happily and cannot master the sports skills in the physical education class, which leads to the fact that students cannot engage in physical exercise well in the time outside the physical education class.

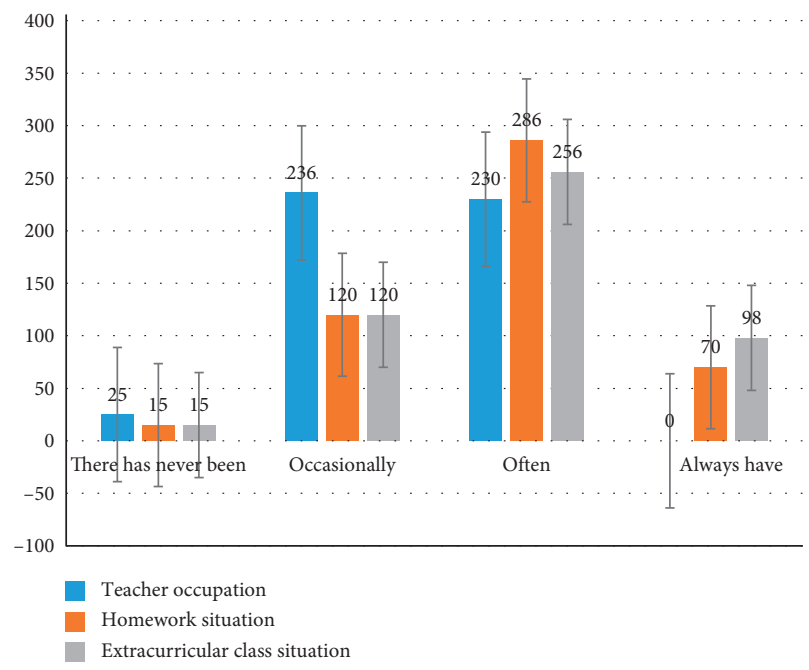

FIGURE 4: Statistics of other teachers' occupation of physical education class and students' homework.

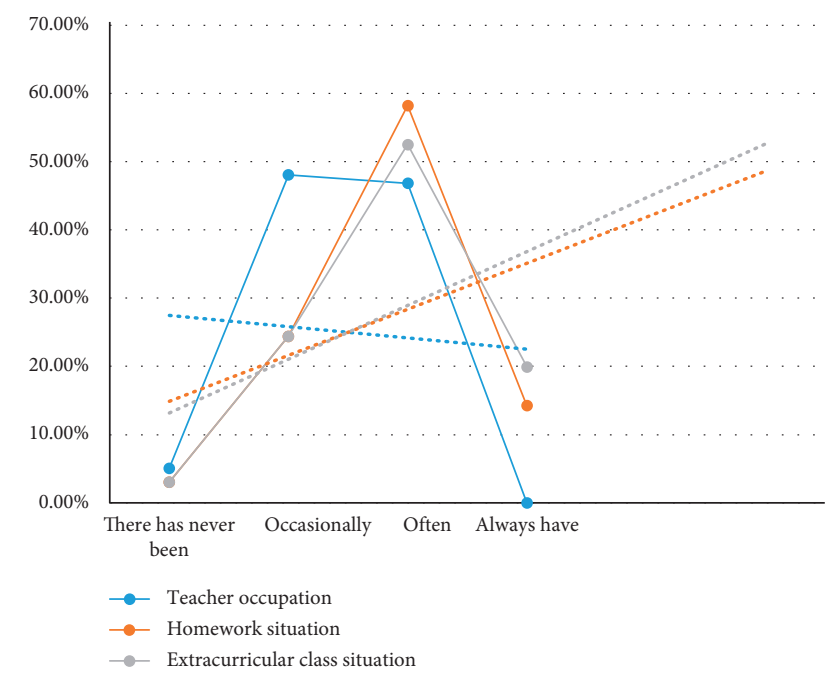

FIgURE 5: The proportion of other teachers in physical education classes and the proportion of students' homework. 
TABLE 3: Questionnaire for students' attitudes towards physical education and classroom content.

\begin{tabular}{lcccccccc}
\hline & Hate & Dislike & Like & Like very much & Boring & The content is too single & Interesting & Colorful \\
\hline Number of people & 39 & 90 & 251 & 111 & 238 & 206 & 37 & 10 \\
Proportion & $7.94 \%$ & $18.33 \%$ & $51.12 \%$ & $22.61 \%$ & $48.47 \%$ & $41.96 \%$ & $7.54 \%$ & $2.04 \%$ \\
\hline
\end{tabular}

TABle 4: Physical education class organization form survey form.

\begin{tabular}{lccc}
\hline & Personal practice & Teamwork & Combination of individual exercises and group exercises \\
\hline Number of people & 256 & 214 & 21 \\
Proportion & $52.14 \%$ & $43.58 \%$ & $4.28 \%$ \\
\hline
\end{tabular}

Table 5: An investigation on the practice of combining physical education between physical education teachers and parents $(n=25)$.

\begin{tabular}{|c|c|c|c|c|c|c|}
\hline \multirow{2}{*}{ Details of the investigation } & \multicolumn{2}{|r|}{ Often } & \multicolumn{2}{|c|}{ Occasionally } & \multicolumn{2}{|c|}{ Never } \\
\hline & Frequency & Percentage (\%) & Frequency & Percentage $(\%)$ & Frequency & Percentage $(\%)$ \\
\hline $\begin{array}{l}\text { You will give students a home for physical } \\
\text { education homework? }\end{array}$ & 11 & 44 & 9 & 38 & 5 & 18 \\
\hline $\begin{array}{l}\text { Will you take the initiative to report to the parents } \\
\text { the students' physical performance and physical } \\
\text { health at school? }\end{array}$ & 5 & 19 & 14 & 55 & 6 & 26 \\
\hline $\begin{array}{l}\text { You will learn from parents about students' sports } \\
\text { activities at home or during holidays? }\end{array}$ & 2 & 10 & 12 & 47 & 11 & 43 \\
\hline $\begin{array}{l}\text { Would you ask students to invite their parents to } \\
\text { participate in sports activities at home? }\end{array}$ & 10 & 41 & 12 & 47 & 3 & 12 \\
\hline $\begin{array}{l}\text { In organizing and planning parent-child } \\
\text { activities, you will solicit the opinions of parents? }\end{array}$ & 2 & 9 & 10 & 39 & 13 & 52 \\
\hline
\end{tabular}

Through field investigations, it is found that in the physical education classroom, teachers simply emphasize the students' achievement of the standard while ignoring the procedural evaluation, so that even if the students with poor physique are very serious in class, they are only in the final assessment. Value the students' final test scores, and finally ignore the process of the students' hard work. As a result, the students who usually go to class very hard have no great sense of accomplishment in the physical education class, and even have a sense of frustration, which makes their interest in physical education weaken, hits students' interest in physical education, and makes students unwilling to participate in sports. This has seriously affected the development of students' physical fitness.

\subsection{A Survey of Physical Education Teachers and Parents in the} Practice of Combining Physical Education. It can be seen from Table 5 that most physical education teachers will assign home physical education homework to students or ask students to invite their parents to participate in physical activities at home. This shows that physical education teachers have realized that school physical education alone cannot fully promote the physical health of students; families need to cooperate in promoting the physical health of students, but it is not deep enough and not systematic enough. It is necessary to further guide or even stipulate that physical education teachers should combine home-school sports with work in a deeper and tacit understanding. For example, if you live in a high-rise building, adults and children can "reject the elevator" together, and they can also have a stair-climbing competition during holidays. This is a great sport. In family "sports," the form of exercise is secondary. The important thing is that the whole family relaxes in common activities and feels the pleasure of leisure.

\section{Conclusions}

The physical health promotion model teaching system is a networked and intelligent teaching platform. Its appearance is to increase the analysis function of the learner's learning ability and learning level on the basis of the traditional teaching platform. The physical health promotion model teaching system that adopts different learning strategies for learners. The use of physical fitness promotion model teaching system can transform learners from a fixed learning route to a targeted dynamic teaching model. As far as teachers are concerned, a complete physical health promotion model teaching system can simplify their teaching process and reduce the teaching preparation cycle. At the same time, it plays an important role in the in-depth exploration of educational resources. Based on big data and artificial intelligence technology, the personalized primary school students' physical health promotion model teaching system is based on the traditional physical health promotion system. In terms of expanding educational resources and digging in-depth educational significance, deep learning algorithms are used to make reasonable improvements. Make the intelligent teaching system more intelligent. At the same time, in the system development stage, this research 
proposes an application development architecture based on big data and artificial intelligence technology language, making full use of the simplicity, cross-platform, and crossapplication characteristics of artificial intelligence technology to provide the individuality of the research. The teaching system of promoting the physical health of primary school students provides a guarantee for the development. The user interest model based on deep learning algorithm is analyzed and used, an optimization plan for the traditional health promotion model teaching system is proposed, and the system function realization is given. The optimized user interest model is a combination of two traditional user interest models, that is, a combination of static user interest model and behavioral interest model, which ensures that under the condition that the learner uses the same way, it can be better for the learner. Interesting learning content is provided. It reduces the time of information filtering for learners, thereby increasing the learning efficiency of learners in the physical health promotion model teaching system. Create a better atmosphere for exercise.

\section{Data Availability}

No data were used to support this study.

\section{Disclosure}

The authors confirm that the content of the manuscript has not been published or submitted for publication elsewhere.

\section{Conflicts of Interest}

The authors declare that there are no conflicts of interest.

\section{Acknowledgments}

This work was supported by Key Projects of the National Social Science Foundation of China (Grant no. 20ATY005) and the Science Foundation of Ministry of Education of China (Grant no. 20YJA890037).

\section{References}

[1] S. S. Kim, Y. J. Kim, E. Carayannis et al., "The effect of compliance knowledge and compliance support systems on information security compliance behavior," Journal of Knowledge Management, vol. 40, pp. 986-1010, 2017.

[2] E. E. Haji and A. Azmani, "Proposal of a digital ecosystem based on big data and artificial intelligence to support educational and vocational guidance," International Journal of Modern Education and Computer Science, vol. 12, no. 4, pp. 1-11, 2020.

[3] R. J. Boratia, J. M. D. Torres, E. G. Ibort et al., "Diferencias en la percepción de actividad física en escolares de sexto de primaria. Retos: nuevas tendencias en educación Física," Deporte Y Recreación, vol. 37, pp. 455-459, 2020.

[4] Z. Lv and L. Qiao, "Analysis of healthcare big data," Future Generation Computer Systems, vol. 109, pp. 103-110, 2020.

[5] M. Ali, L. Tang Jung, A.-H. Abdel-Aty, M. Y. Abubakar, M. Elhoseny, and I. Ali, "Semantic-k-NN algorithm: an enhanced version of traditional k-NN algorithm," Expert Systems with Applications, vol. 151, no. 1, Article ID 113374, 2020.

[6] K. P. Gürkan and D. Ayar, "The impact of e-health literacy on health promotion behaviors of high school students," The Journal of Pediatric Research, vol. 7, no. 4, pp. 286-292, 2020.

[7] B. Hyndman, A. C. Benson, L. Lester et al., "Is there a relationship between primary school children's enjoyment of recess physical activities and health-related quality of life? a cross-sectional exploratory study," Health Promotion Journal of Australia Official Journal of Australian Association of Health Promotion Professionals, vol. 28, no. 1, pp. 37-43, 2016.

[8] C. Kunierz, "The goals and objectives of current physical education. the opinions of teachers from the south-west region of Poland," Health Promotion \& Physical Activity, vol. 2, no. 3, pp. 79-94, 2017.

[9] S. Li, "Synesthetic design of digital elderly products based on big data," Wireless Communications and Mobile Computing, vol. 2021, Article ID 5596571, 9 pages, 2021.

[10] A. Massaro, G. Panarosa, N. Savino et al., "Advanced multimedia platform based on big data and artificial intelligence improving cybersecurity," International Journal of Network Security \& Its Applications, vol. 12, no. 3, pp. 23-37, 2020.

[11] H. Zhu, "Big data and artificial intelligence modeling for drug discovery," Annual Review of Pharmacology and Toxicology, vol. 60, no. 1, pp. 573-589, 2020.

[12] H. C. Kang and J. W. Jwa, "Development of android based smart tourism application based on tourism bigdata analytics," Journal of Engineering and Applied Sciences, vol. 13, no. 5, pp. 1164-1169, 2018.

[13] W. J. Jang, J. Y. Kim, B. T. Lim et al., "A study on data profiling based on the statistical analysis for big data quality diagnosis," International Journal of Advanced Science and Technology, vol. 117, pp. 77-88, 2018.

[14] P. Xiao, D. Q. Hou, A. Y. Gao et al., "The association between blood lipids and calcaneus bone mineral density in children and adolescents aged 6-16 years in Beijing," Zhonghua Yu Fang Yi Xue Za Zhi [Chinese Journal of Preventive Medicine], vol. 53, no. 2, pp. 196-201, 2019.

[15] M. Kopa, A. Grochowska, and W. Brończyk, "Food preferences of tarnów primary school children in the context of the occurrence of obesity," Health Promotion \& Physical Activity, vol. 1, no. 1, pp. 47-60, 2016.

[16] K. D. Spoor and H. Madanat, "Relationship between body image discrepancy and intuitive eating," International Quarterly of Community Health Education, vol. 36, no. 3, pp. 189-197, 2016.

[17] A. Tokairin, G. F. Seixas, N. Silva et al., "Avaliao do conhecimento de escolares sobre saúde bucal, dieta e higiene: ferramenta diagnóstica para direcionamento de atividade educativa," Revista de Ensino Educação e Ciências Humanas, vol. 21, no. 3, pp. 365-369, 2020.

[18] T. Yang, Z. Qian, Q. Gan et al., "Scheme of the "nutrition campus" pilot program," Wei Sheng Yan Jiu=Journal of Hygiene Research, vol. 46, no. 5, pp. 717-721, 2017.

[19] R. D. Renard, "Creating the other requires defining Thainess against which the other can exist: early-twentieth century definitions (Redefining"otherness"from Northern Thailand)," Tonan Ajia Kenkyū, vol. 44, no. 3, pp. 295-320, 2017.

[20] F. Javier, J. V. Alonso, M. V. Álvarez et al., "Physical fitness as an indicator of health status and its relationship to academic performance during the prepubertal period," Health Promotion Perspectives, vol. 7, no. 4, pp. 197-204, 2017. 
[21] B. Baldursdottir, R. E. T Ae Htinen, I. D. Sigfusdottir et al., "Impact of a physical activity intervention on adolescents' subjective sleep quality: a pilot study," Global Health Promotion, vol. 24, no. 4, pp. 14-22, 2017.

[22] J. R. ER Fernández DíazP. J. Neira-Martín et al., “Actividad física realizada por escolares espaoles según edad y género. Retos: nuevas tendencias en educación Física," Deporte $Y$ Recreación, vol. 99, no. 39, pp. 238-245, 2020.

[23] W. Wojtanowski, P. Kozio, and A. Jankowicz-Szymańska, "The correlation between the pelvic movement symmetry during motion, as well as body mass and the alignment of the knees of schoolchildren," Health Promotion \& Physical Activity, vol. 12, no. 3, pp. 16-21, 2020.

[24] B. Jasmin, R. Snežana, J. Goran et al., "Health related physical fitness of Bosnian-Herzegovinian and Serbian primary school students," Fizicka Kultura, vol. 70, no. 1, pp. 55-69, 2016.

[25] K. Devries, H. Kuper, L. Knight et al., "Reducing physical violence toward primary school students with disabilities," Journal of Adolescent Health, vol. 62, no. 3, pp. 303-310, 2018.

[26] O. O. Osadolor, "Gingival health status of primary school children in a Nigerian community," Update Dental College Journal, vol. 11, no. 1, pp. 16-19, 2021.

[27] R. Jago, M. J. Edwards, S. J. Sebire et al., "Bristol Girls Dance Project: a cluster randomised controlled trial of an afterschool dance programme to increase physical activity among 11- to 12-year-old girls," BMC Public Health, vol. 4, no. 6, pp. 1-7, 2016. 